\title{
Techno-economic analysis on a small-scale organic Rankine cycle with improved thermal driven pump
}

\author{
L. Jianga, ${ }^{\mathrm{a},}$, R.Q. Wang ${ }^{\mathrm{b}}$, A.P. Roskilly ${ }^{\mathrm{b}}$ \\ ${ }^{b}$ School of Engineering, University of Aberdeen, Aberdeen, AB24 3UE, UK \\ ${ }^{b}$ School of Engineering, Durham University, Durham DH1 3LE, UK \\ *Corresponding author. Email: maomaojianglong@126.com
}

\begin{abstract}
Thermal driven pump is usually defined as a thermodynamic way which plays a similar role to replace common electricity driven pump. In this paper, a concept of improved thermal driven pump series is introduced to small-scale organic Rankine cycle and the up-limit thermal efficiency is explored by using discrete dividing method. Results indicate that power outputs of organic Rankine cycle by using thermal driven pump $\mathrm{V}_{2}$ range from $158.8 \mathrm{~W}$ to $343.1 \mathrm{~W}$ which are improved by up to $73.5 \%$ when compared with that using previous type $V_{1}$. Energy and exergy efficiencies using improved type $\mathrm{V}_{2}$ and $\mathrm{V}_{3}$ increase from 0.018 to 0.043 and from 0.145 to 0.246 , respectively. The largest increment could reach $40.5 \%$ and the highest value could account for $85 \%$ of the up-limit performance. Influencing factors i.e. mass ratio and pump efficiency are defined to further evaluate the performance in the possible applications. One remarkable inspiration is that organic Rankine cycle by using improved thermal driven pump may be an alternative solution to conventional type which could achieve the better techno-economic performance only under the conditions of dividing number smaller than 4 and the scale less than $10 \mathrm{~kW}$.
\end{abstract}

Keywords: Organic Rankine cycle; Improved thermal driven pump; Small scale; Thermal efficiency 


\section{Nomenclature}

A

C

CEPCI

D

E

EDP

$h$

K

M

$m$

ODP

$P$

$\operatorname{Pr}$

Q

$R$

$R e$

$r$

SIC

$T$

TDP

$\mathrm{T}_{0}$

$t$

$U$

V

W

$\eta$

$\lambda$

$\alpha$
Area, $\mathrm{m}^{2}$

Specific heat, $\mathrm{kJ} \cdot \mathrm{kg}^{-1} \cdot \mathrm{K}^{-1}$

Chemical engineering plant cost index

Diameter, $\mathrm{m}$

Exergy, kW

Electricity driven pump

Specific enthalpy, $\mathrm{kJ} \cdot \mathrm{kg}^{-1}$

Heat transfer coefficient, $\mathrm{W} \cdot \mathrm{m}^{-2} \cdot \mathrm{K}^{-1}$

Mass, kg

Mass flow rate, $\mathrm{kg} \cdot \mathrm{s}^{-1}$

Ozone Depletion Potential

Power, kW

Prandtl number

Heat, kW

Fouling resistance, $\mathrm{m}^{2} \cdot \mathrm{K} \cdot \mathrm{W}^{-1}$

Reynolds number

Radius, $\mathrm{m}$

Specific investment cost, $\$ \cdot \mathrm{kW}^{-1}$

Temperature, $\mathrm{K}$

Thermal driven pump

Environment temperature, ${ }^{\circ} \mathrm{C}$

Time, s

Total internal energy, $\mathrm{kJ}$

Volume, $\mathrm{m}^{3}$

Work, W

\section{Efficiency}

Heat conductivity, $\mathrm{W} \cdot \mathrm{m}^{-1} \cdot \mathrm{K}^{-1}$

Convective heat transfer coefficient, $\mathrm{W} \cdot \mathrm{m}^{-2} \cdot \mathrm{K}^{-1}$ 


\section{Subscripts}

ave

en

e

ex

$\exp$

h

hw

hx

in

1

out

pu

rec

ref

res

S

up

v

w
Average

Energy

Evaporator

Exergy

Expander

Heat

Hot water

Heat exchanger

Inlet

Liquid

Outlet

Pump

Receiver

Refrigerant

Residual

Conversion

Up-limit

Vapour

Water

\section{Introduction}

Statistics have revealed that more than $50 \%$ of industrial waste heat is within low-grade range [1]. For middle and low temperature heat source, an increasing number of achievements is obtained to enhance system efficiency. Comparably, considerable low grade thermal energy below $100^{\circ} \mathrm{C}$ is still being wasted, which is disadvantageous to the environment and carbon footprint [2]. Thus it is quite desirable to recover these small-scale and low-temperature heat sources by developing the relevant high-efficient technologies, which could contribute to reducing total amount of wastes heat, increasing energy output and realizing sustainable development. Various technologies could be used for 
recovering low grade heat below $100^{\circ} \mathrm{C}$, e.g. heat to power [3] and heat to refrigeration [4]. Currently, thermal driven refrigeration is still gathering the momentum due to the relatively high energy conversion efficiency when the temperature is lower than $100^{\circ} \mathrm{C}$. However, cooling demands are not always desirable and required. Thus electricity is more flexible to be adopted in various applications with regard to different demands of end users. Organic Rankine cycle (ORC) could be a good candidate for power generation [5]. Similar to Rankine cycle, ORC replaces water with organic working fluid, which is characterized as simple structure and flexible adjustment. Organic working fluids used in ORC facilitate waste heat recovery at the relatively low temperatures using small-scale devices. It is acknowledged that improving thermal efficiency is one of the ultimate goals for ORC investigations which is often related with novel working fluid development and system optimization [6, 7].

For the ORC researches of working fluids, the common pure types e.g. R134a, R245fa, R123 and $\mathrm{n}$-pentane have been widely and comprehensively investigated in the past few decades [8,9]. These researches mainly aim to select the suitable working fluids based on their thermal performance i.e. energy and exergy efficiency of different working cycles [10]. After that, zeotropic working fluids become another hot topic for the application of ORCs. But the core concepts of the fluid selection are similar with that of pure type [11]. Several review articles have given a clear landscape of selecting pure and zeotropic working fluids for ORC when considering the influence of their properties and categories on the thermal performance $[12,13]$. However, the selection method has a limited understanding of its mechanism though it has pointed out the general performance of the working fluids. Thus in recent years, more studies have explored the relationship between thermophysical properties and the performance by using quantitive method and the key affecting parameters could be directly revealed [14]. However, the main issue of the quantitive method is not completely coherent at the current stage due to the different assumptions and working conditions in the analyzing processes $[15,16]$. Therefore, the researches on working fluids will continue to be further investigated by using various methods [17].

The other solution is to optimize the system configuration by improving the working efficiency of each component. The most investigated part is the expander since it is directly related with the power output. Burgeoning researches of ORC focus on varies working types of expanders e.g. radial turbine [18], scroll expander [19], screw expander [20] and free piston expander [21] applied for the different 
heat sources e.g. solar, geothermal and other industrial waste heat. Considering the heat exchangers, the main methods still lie in the heat transfer enhancement in terms of different design types [22]. Compared with the expander and heat exchanger, researches on electricity driven pump (EDP) for ORC is quite scare. Few related studies discussed the multistage centrifugal pump or gear pump which showed that the working efficiency had a remarkable influence on the system performance of ORC [23, 24]. However, in some research cases, the pump work is often selectively ignored. For the large-scale application, pump work accounts for a very small part of energy consumption i.e. less than $3 \%$ which has almost no influence on energy efficiency. Comparably, this part of electricity cannot be neglected for small-scale ORC systems [25]. This could be even more valuable when the working conditions become severe e.g. relatively low heat source temperature, high condensation temperature and low system compactness required [26]. To solve this problem, some innovative concepts have been carried out to create the same pressure difference by replacing the EDP with other kind of virtual pump without consuming the electricity e.g. gravity driven pump [27], thermal driven pump (TDP) [28], and combined driven pump. However, these virtual pumps could improve the thermal efficiency while bringing some other problems or limitations e.g. the required system height, output continuity and thermal stability. One of the good instances is our previous work that established a lab-scale experimental rig of ORC with TDP to have a good understanding of its working performance. Although energy efficiency of the system could be improved by $31 \%$, the switch interval leaded to the non-continuous and low power output [29]. To increase the power output, a new version of the experimental rig with TDP was established. Nonetheless, 1-minute interval still caused the unstable output though $90 \%$ of the process is stable [30]. Performance stability should be taken the priority for ORC with TDP so that it could be compared to that with EDP.

This paper presents a novel concept of improved TDP series for small-scale ORC. Thermal and economic performance of ORC by using TDP series are first analyzed and compared in terms of energy efficiency, power output, thermal stability, capital cost, etc. The optimal dividing number and suitable working conditions are summarized as the key guideline. The overarching framework of this paper is elaborated as follows: Basic ORC is briefly introduced and then the concept of TDP is illustrated. TDP for absorption power generation is elaborated and improved TDP series for ORC are presented. Thermal performance of ORC with improved TDP series is compared with that using previous type. 
Then a summary of power cycles with gravity and TDP is presented which is followed by conclusions.

\section{System description}

Fig. 1 indicates the schematic diagram of conventional ORC, which is mainly composed of two heat exchangers, an expander and an EDP. Its principle is the same with that of Rankine cycle. The conventional ORC may enjoy a very low energy efficiency due to the large energy consumption of the EDP when heat temperature is low and rated power output of system is small. To solve this problem, EDP in Fig. 1 could be replaced with TDP in Fig. 2 which is presented in our previous work [31]. To discriminate descriptions in the rest of paper, TDP- $\mathrm{V}_{1}$ refers to the version used in our previous work when compared with improved TDP series i.e. TDP- $\mathrm{V}_{2}$ to $T D P-\mathrm{V}_{\mathrm{n}}$ presented in this paper. TDP- $\mathrm{V}_{1}$ and improve TDP series are summarized as TDP series i.e.TDP- $\mathrm{V}_{1}$ to TDP- $\mathrm{V}_{\mathrm{n}}$.

ORC with TDP- $\mathrm{V}_{1}$ is mainly composed of two high-efficient heat exchangers, an expander, a generator and other auxiliary components. The working processes consist of a pre-expansion process and a power generation process, which are briefly illustrated as shown in Fig. 2a: (a) Pre-expansion process. Heat exchanger 1 acts as an evaporator while heat exchanger 2 works as a condenser. Water valves V2, V4, V5 and V7 are open, and all other valves are closed. Evaporator undertakes an isochoric heating process while condenser takes an isochoric cooling process. (b) Power generation process. When pressure of evaporator becomes constant and condenser achieves a cooler level, open RV1 and RV3. Then working fluid from the evaporator flows into the expander. The power is generated until no pressure difference exists. When the generator doesn't produce power, close RV1, RV3, V2, V4, V5 and V7. Then heat exchanger 1 and 2 swap their roles. The next cycle starts as indicated in Fig. 2b, which is similar to previous two processes. Working mode for ORC with TDP- $\mathrm{V}_{1}$ could be according to Table 1. Heat exchanger 1 and 2 are always heated and cooled reversely. Pre-expansion process doesn't contribute power output and reduces the average output.

EDP is replaced by TDP i.e. the switch of two heat exchangers as shown in the dash area of Fig. 2. Compared with conventional ORC, ORC with TDP has a higher energy efficiency due to no energy consumption of the pump. But a continuous power output is obtained in power generation process, i.e. no output in pre-expansion process. To solve this problem of the continuity, two or more ORCs with TDP- $\mathrm{V}_{1}$ are regarded to be alternatively used. However, power output is still not stable which leads to 
the energy loss at the beginning and the end of power generation process. This disadvantage cannot be overcome only by using TDP- $\mathrm{V}_{1}$. It is quite desirable to seek other solutions for continuous and stable power output.

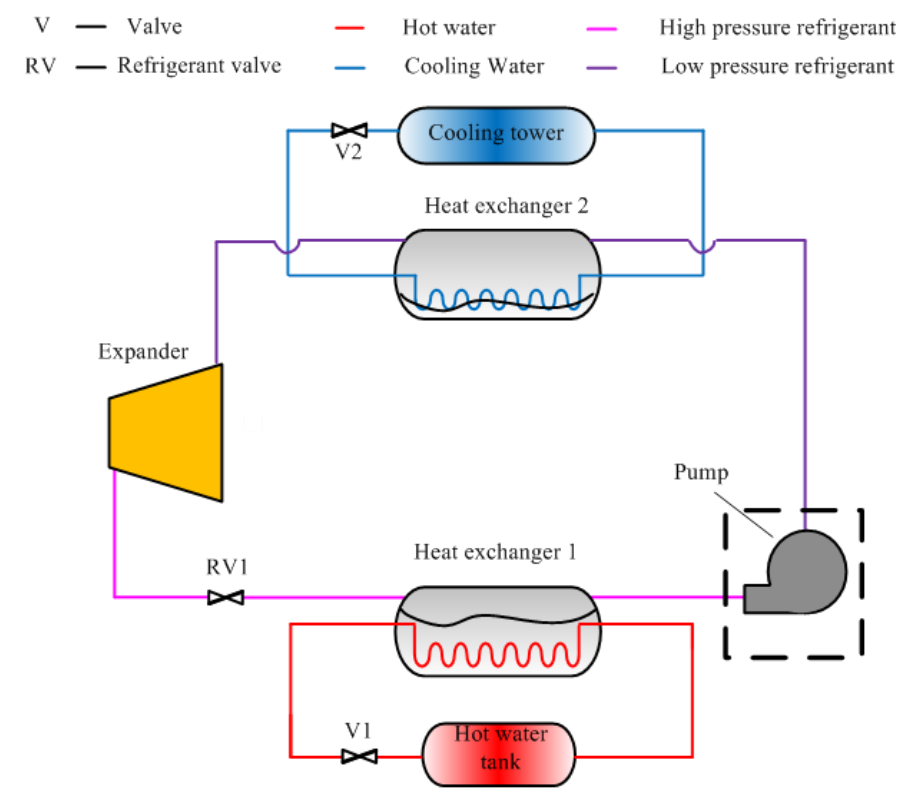

Fig. 1. Schematic diagram of a conventional ORC.

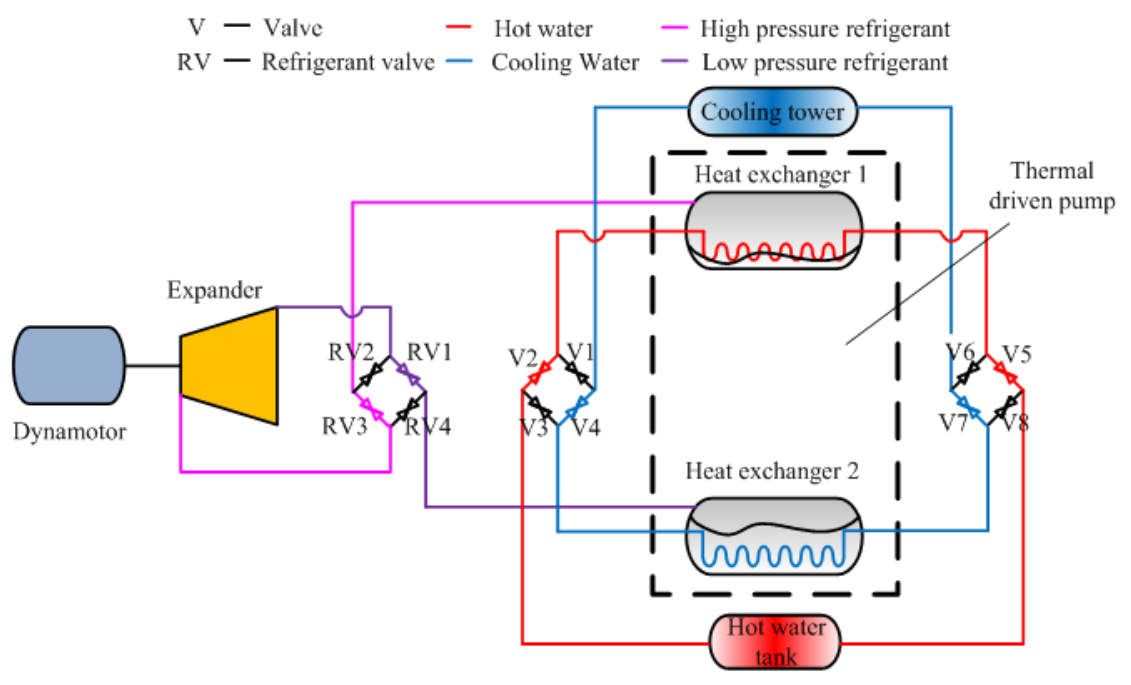

(a) 


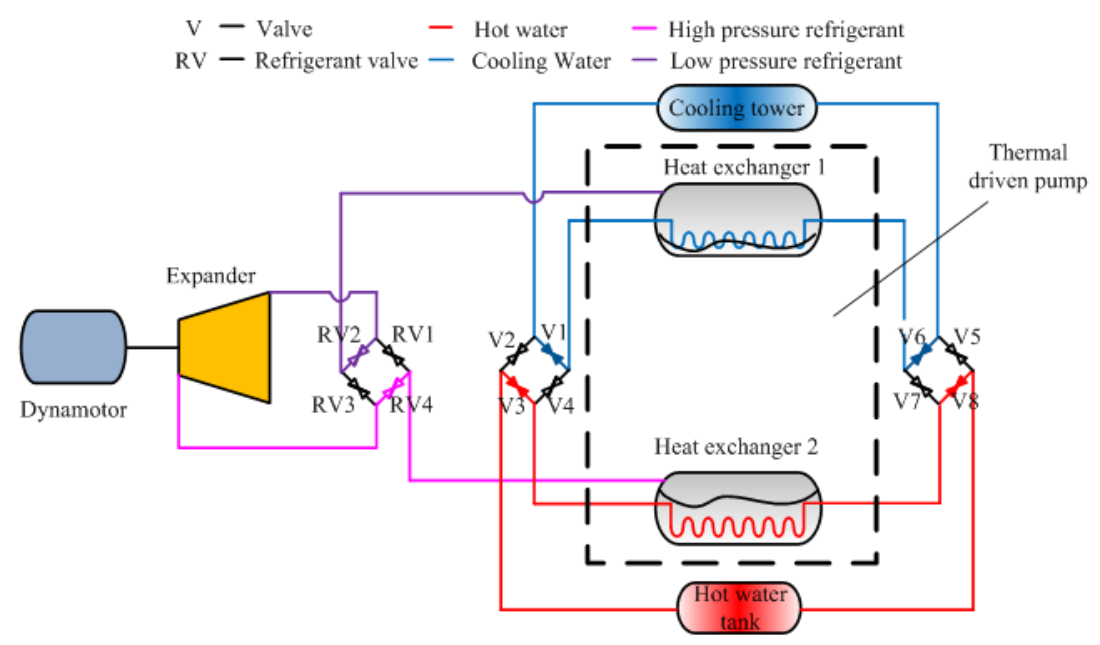

(b)

Fig. 2. Schematic diagram of ORC with TDP- $\mathrm{V}_{1}$ (a) first cycle; (b) next cycle [31].

Table 1. Working mode for ORC with TDP- $\mathrm{V}_{1}$.

\begin{tabular}{ccccc}
\hline & \multicolumn{4}{c}{ Working mode } \\
\hline & Pre-expansion & Power generation & Pre-expansion & Power generation \\
\hline Heat exchanger 1 & Heating & Heating & Cooling & Cooling \\
Heat exchanger 2 & Cooling & Cooling & Heating & Heating \\
Power & Unable & Able & Unable & Able \\
\hline
\end{tabular}

Recently, a concept of respiratory pump comes from absorption cycle, which is renowned as the continuous thermal cycle with regard to various functions of power, heating and cooling [32]. Fig. 3 displays ammonia absorption cycle for power generation. Fig. 3a is a basic absorption cycle which is composed of an absorber, a generator, a pump, an expander, a dynamotor and several valves. Comparably, Fig. $3 \mathrm{~b}$ presents a absorption cycle using a respiratory pump. Different from $T D P-V_{1}$ above by using the switch of two heat exchangers, three liquid tanks i.e. reactor 1,2 and 3 are arranged in vertical direction which are defined as respiratory pump. Thus continuous and stable power output could be achieved by using these reactors. The concerning processes are illustrated in terms of low pressure and high pressure side. For low pressure side, reactor 1 is connected to absorber. V3 and V4 are one-way valve. Close V2 and open V1 as shown in Fig. 4a. Reactor 1 is connected to reactor 2, and pressure will be quickly balanced through V1; Working fluid in reactor 1 flows into reactor 2 through V3 due to the gravity of fluid. The amount of working fluid in reactor 1 decreases and the amount in reactor 2 increases. In this 
process, ammonia-water solution in reactor 3 continuously flows into generator and heated. The desorbed ammonia is expanded to produce the power. When the solution in reactor 3 is less than required capacity. Then close V1 and open V2 as shown in Fig. 4b. Reactor 2 is connected to reactor 3, and high-pressure ammonia passes through V4. Pressure in two reactors is rapidly balanced, and the solution in reactor 2 flows into reactor 3 through V4. The solution amount in reactor 2 decreases while the amount in reactor 3 increases. Thus ammonia solution constantly flows into the generator, and a continuous power output could be realized through this thermal and gravity driven pump.

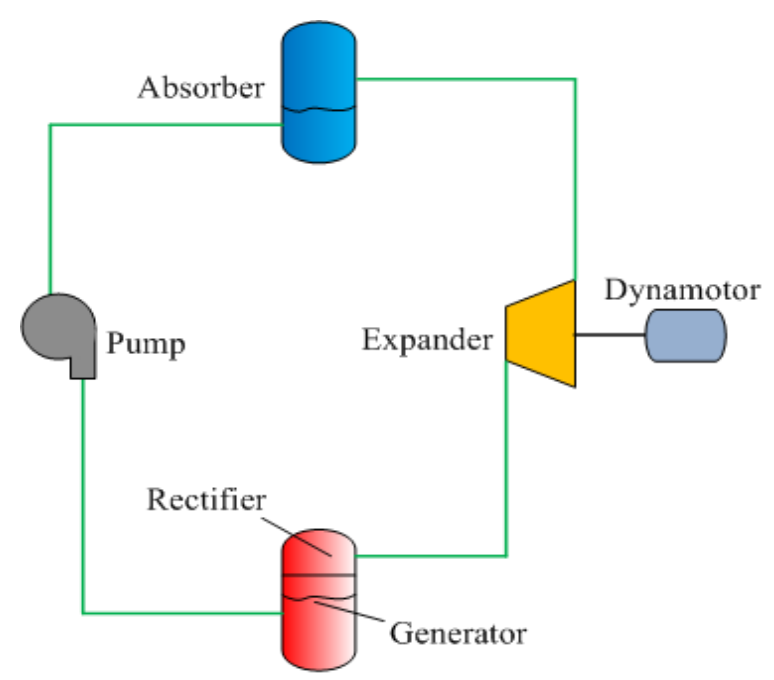

(a)

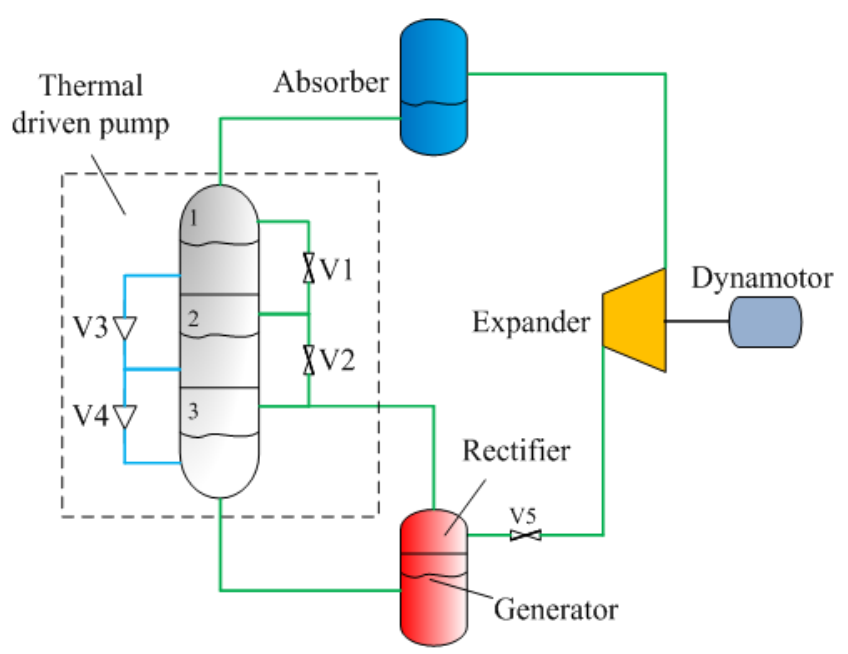

(b)

Fig. 3. Schematic diagram of ammonia-water absorption cycle for power generation (a) basic cycle; (b) cycle using respiratory pump $[32,33]$. 


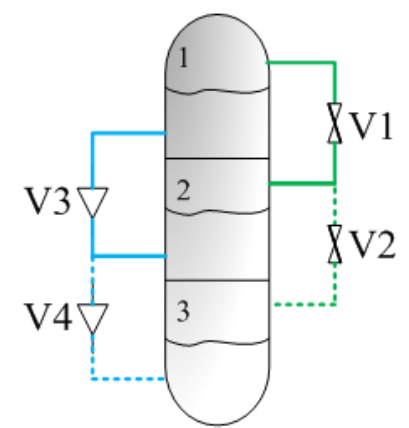

(a)

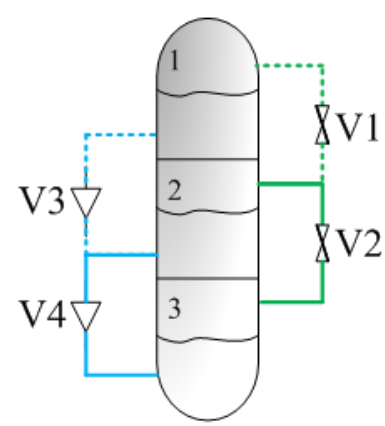

(b)

Fig. 4. Working processes of respiratory pump (a) low pressure side; (b) high pressure side.

Based on respiratory pump from absorption cycle, ORC by using TDP- $\mathrm{V}_{2}$ is presented for continuous and stable power output. The basic concept is to replace ammonia-water solution with the refrigerant in Fig. 3. To further improve the system compactness, reactor 1 is combined with absorber while reactor 3 is merged with generator. Thus ORC with TDP- $\mathrm{V}_{2}$ is presented as shown in Fig. 5. It is mainly composed of three heat exchangers i.e. heat exchanger 1-3, an expander, a dynamotor and other auxiliary equipment. Heat exchanger 1 and 2 act as condenser and receiver alternatively which should place higher than heat exchanger 3 as the evaporator.

The working process is elaborated as follows: Heat exchanger 3 is always heated during all the processes. The first working cycle is shown in Fig. $5 \mathrm{a}$. In this process, heat exchanger 2 is heated whereas heat exchanger 1 is cooled. The refrigerant with high temperature and pressure from heat exchanger 3 flows into the expander and generate power. The expanded refrigerant is then condensed in heat exchanger 1. Due to the connection between heat exchanger 2 and 3 , the pressure will be balanced at a certain time since they are heated by the same heat source. The liquid refrigerant then flows into heat exchanger 3 owing to the effect of gravity. When liquid refrigerant almost runs out, heat exchanger 2 will be cooled by changing the direction of V1 and V6. When liquid refrigerant is lower than standard value i.e. power output may occur unstable, heat exchanger 1 will be heated while heat exchanger 2 starts to be cooled for the next cycle as shown in Fig. 5b. Similarly, the refrigerant from heat exchanger 3 flows into the expander and it is condensed in heat exchanger 2 . The pressure between heat exchanger 1 and 3 will be balanced since they are heated by the same heat source. Then liquid refrigerant will flow into heat exchanger 3. When liquid refrigerant almost runs out, heat exchanger 1 will be cooled by cooling tower. When work output is not stable, heat exchanger 1 will replace the role of heat exchange 2 . The rest 
working processes are similar with that above. The dash line will be connected in case that pressure of two reactors are balanced. Table 2 indicates the detailed working processes of each heat exchanger for ORC using TDP- $\mathrm{V}_{2}$. Heat exchanger 3 is always heated whereas heat exchanger 1 and 2 swap their roles in most of working time. Different from ORC with $\mathrm{TDP}-\mathrm{V}_{1}$, another heat exchanger is prepared for power generation ahead of time i.e. working mode 2 and 4 . Thus heat exchanger 3 i.e. evaporator generates the power in all working processes.

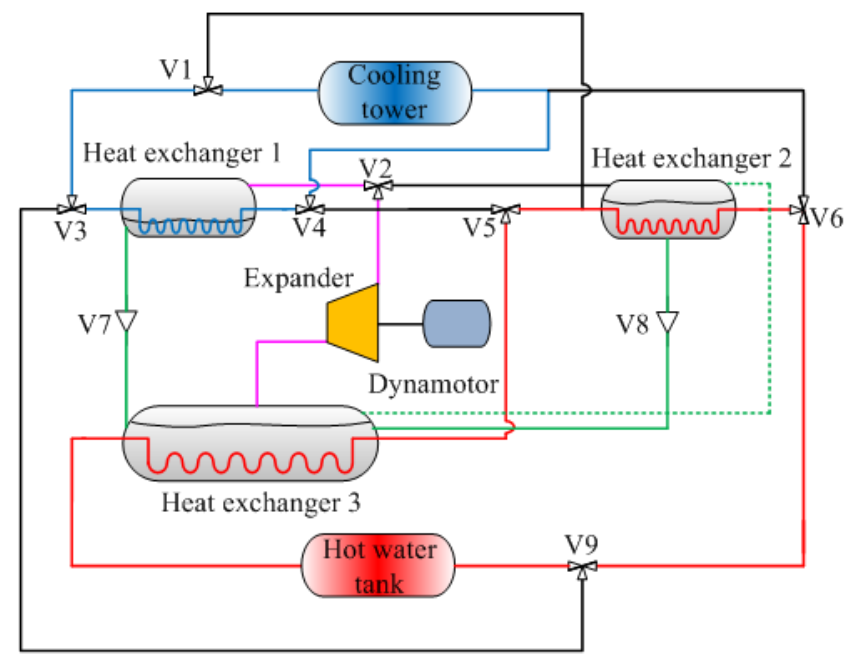

(a)

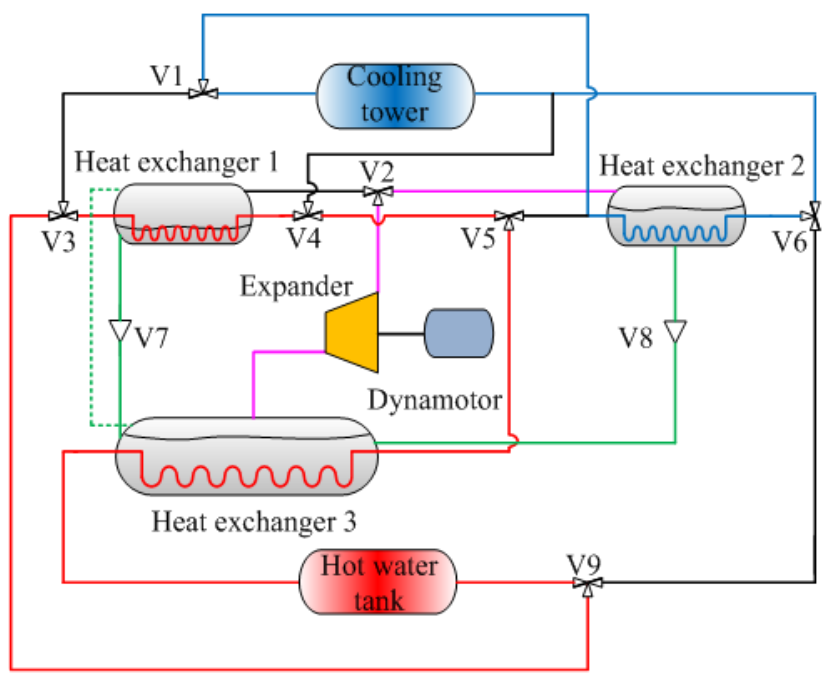

(b)

Fig. 5. Schematic diagram of ORC with TDP- $\mathrm{V}_{2}$ (a) first cycle; (b) next cycle.

Table 2. Working mode for ORC with TDP- $\mathrm{V}_{2}$. 


\begin{tabular}{ccccc}
\hline & \multicolumn{4}{c}{ Working mode } \\
\hline & 1 & 2 & 3 & 4 \\
\hline HX3 & Heating & Heating & Heating & Heating \\
HX2 & Heating & Cooling & Cooling & Cooling \\
HX1 & Cooling & Cooling & Heating & Cooling \\
Power & Able & Able & Able & Able \\
\hline
\end{tabular}

The ORC with TDP- $\mathrm{V}_{2}$ could achieve the continuous output through an additional heat exchanger part which includes heat exchanger, pipe, gas and liquid refrigerant. The condenser in Fig. 2 is divided into condenser and receiver as shown in Fig. 5. Following this concept of TDP-V $\mathrm{V}_{2}$, it tends to consider that the condenser could be further divided into more heat exchangers, and a general concept of TDP series i.e. TDP- $\mathrm{V}_{\mathrm{n}}$ could be summarized and proposed as shown in Fig. 6. When $\mathrm{N}$ is 1 , it is exactly TDP- $V_{1}$ i.e. one condenser in our previous work. When $\mathrm{N}$ is more than 1 , it is the improved TDP series i.e. TDP- $V_{2}$ to TDP- $V_{n}$. It is demonstrated that the improved TDP series may take the advantages of the large heat transfer area, continuous and high power output, which could result in a high thermal efficiency. When the divided number $\mathrm{N}$ tends to the infinity i.e. one pair of tiny heat exchangers is always heated and cooled instantly and alternately, the theoretical up-limit thermal efficiency of the ORC with improved TDP series could be close to the performance of conventional ORC without pump under the same working conditions. By using this discrete method, it is clear to further figure out the advantages and disadvantages of TDP series when compared with conventional ORC.

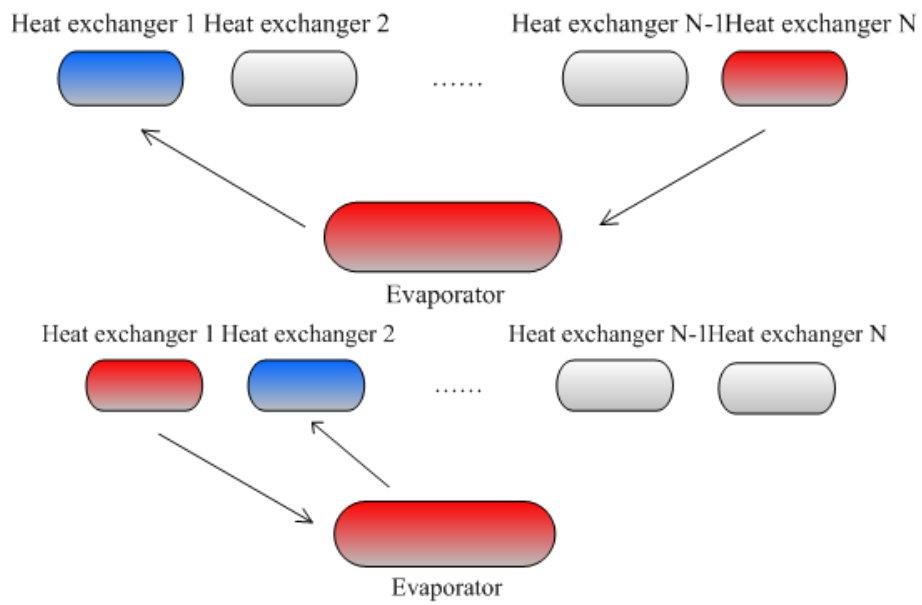




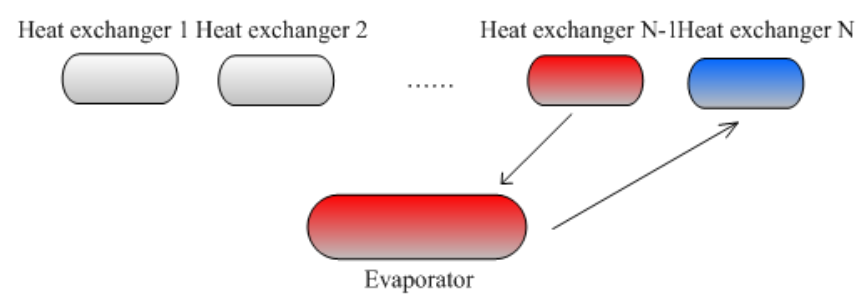

Fig. 6. The general concept of ORC with improved TDP series.

\section{Methodology}

\subsection{Thermal evaluation}

The equations of different components of ORC with TDP series are considered, and thermodynamic processes are established and implemented. Some assumptions are listed as follows: (1) The cycle and their components operate under steady-state conditions. (2) There is a thermodynamic equilibrium at the inlet and outlet of each component. (3) The kinetic of working fluid in the cycles are negligible. (4) Heat loss and pressure drop in the system are negligible.

Total heat input of ORC by using TDP series, which is composed of two parts. One is the heat for the refrigerant; The other is that for metal part of heat exchanger, which could refer to equations 1-3.

$$
\begin{gathered}
Q_{\mathrm{h} 1}=C_{\mathrm{w}} m_{\mathrm{hw}}\left(T_{\mathrm{hw}, \text { in }}-T_{\mathrm{hw}, \text { out }}\right)=\frac{d U_{\mathrm{ref}}}{d t}+\frac{d\left(C_{\mathrm{e}} M_{\mathrm{e}} T_{\mathrm{e}}\right)}{d t} \\
Q_{\mathrm{h} 2}=C_{\mathrm{w}} m_{\mathrm{hw}}\left(T_{\mathrm{hw}, \text { in }}-T_{\mathrm{hw}, \text { out }}\right)=\frac{d U_{\mathrm{ref}}}{d t}+\frac{d\left(C_{\mathrm{rec}, \mathrm{N}} M_{\mathrm{rec}, \mathrm{N}} T_{\mathrm{rec}, \mathrm{N}}\right)}{d t} \\
Q_{\mathrm{h}}=Q_{\mathrm{h} 1}+Q_{\mathrm{h} 2}
\end{gathered}
$$

where $m_{\mathrm{hw}}$ is mass flow rate of hot water; $M_{\mathrm{e}}$ and $M_{\mathrm{rec}}$ are the mass of the evaporator and receiver, $C_{\mathrm{w}}, C_{\mathrm{e}}$ and $C_{\text {rec }}$ are the specific heat of water, evaporator and receiver. $\mathrm{N}$ denotes the heat exchanger $\mathrm{N}$ as shown in Fig. $6(\mathrm{~N} \geq 2)$. When $\mathrm{N}$ is 1 , it means that the $\mathrm{ORC}$ system operates with $\mathrm{TDP}-\mathrm{V}_{1}$ i.e. one condenser and no receiver. When $\mathrm{N}$ is 2 , it indicates the $\mathrm{ORC}$ with $\mathrm{TDP}-\mathrm{V}_{2}$ i.e. one condenser and one receiver. The heat input of equation 2 is for the receiver.

Heat transfer coefficient of the evaporator $K_{\mathrm{e}}$ could be defined as equations 4 and 5 .

$$
\begin{gathered}
K_{\mathrm{e}} A_{\mathrm{e}} \Delta T_{\mathrm{ave}, \mathrm{e}}=C_{\mathrm{w}} m_{\mathrm{hw}}\left(T_{\mathrm{hw}, \text { in }}-T_{\mathrm{hw}, \text { out }}\right) \\
\frac{1}{K_{\mathrm{e}}}=\frac{1}{\alpha_{\mathrm{ref}}}+\frac{A_{\mathrm{e}} \ln \left(r_{2} / r_{1}\right)}{2 \pi \lambda_{\mathrm{cu}} l}+\frac{A_{\mathrm{e}}}{\alpha_{\mathrm{hw}} A_{\mathrm{hw}}}+R_{0}
\end{gathered}
$$

Heat transfer coefficient of the refrigerant $\alpha_{\text {ref }}$ could be defined as equation 6 .

$$
\alpha_{\text {ref }}=C q^{0.67} M_{\mathrm{r}}^{-0.5} P_{\mathrm{r}}^{\mathrm{m}}\left(-\lg P_{\mathrm{r}}\right)^{-0.55}
$$


where the parameters $C$ and $\mathrm{m}$ are $90 \mathrm{~W}^{0.33} \cdot \mathrm{m}^{-0.66} \cdot \mathrm{K}^{-1}$ and $0.12-0.2 \lg \left\{\mathrm{R}_{\mathrm{p}}\right\}_{\mu \mathrm{m}}$, respectively.

Heat transfer coefficient of the water $\alpha_{\mathrm{hw}}$ could be defined as equation 7.

$$
\alpha_{\mathrm{hw}}=0.023\left(\frac{\lambda_{\mathrm{hw}}}{D_{\mathrm{pipe}}}\right) R e_{\mathrm{hw}}^{0.8} P r_{\mathrm{hw}}^{0.5}
$$

The average power output $W_{\text {ave }}$ could refer to equation 8 .

$$
W_{\text {ave }}=m_{\text {ref }} \eta_{s}\left(h_{\text {exp,in }}-h_{\text {exp }, \text { out }}\right)
$$

where $\eta_{\mathrm{s}}$ is conversion efficiency; $h_{\text {exp,in }}$ and $h_{\text {exp,out }}$ are the inlet and outlet enthalpy of the expander.

Energy efficiency of ORC with improved TDP and its up-limit performance could be according to equations 9 and 10.

$$
\begin{gathered}
\eta_{\text {en }}=\frac{W_{\text {ave }}}{Q_{\mathrm{h}}} \\
\eta_{\text {en,up }}=\frac{W_{\text {ave }}}{Q_{\mathrm{h} 1}}
\end{gathered}
$$

Heat exergy of ORC with improved TDP and heat exergy of receiver could refer to equations 11-13.

$$
\begin{gathered}
E_{\mathrm{h} 1}=Q_{\mathrm{h} 1}\left(1-\frac{T_{0}}{T_{\mathrm{h}, \text { ave }}}\right) \\
E_{\mathrm{h} 2}=Q_{\mathrm{h} 2}\left(1-\frac{T_{0}}{T_{\mathrm{h}, \text { ave }}}\right) \\
E_{\mathrm{h}}=E_{\mathrm{h} 1}+E_{\mathrm{h} 2}
\end{gathered}
$$

where $T_{\mathrm{h}, \text { ave }}$ is the average temperature of heat input.

Exergy efficiency of ORC with TDP series and its up-limit performance could be expressed as equations 14 and 15 .

$$
\begin{gathered}
\eta_{\text {ex }}=\frac{W_{\text {ave }}}{E_{\mathrm{h}}} \\
\eta_{\text {ex,up }}=\frac{W_{\text {ave }}}{E_{\mathrm{h} 1}}
\end{gathered}
$$

\subsection{Model validation}

Simulation results are validated by the outputs of an ORC with $\mathrm{TDP}-\mathrm{V}_{1}$ experimental rig in our previous work [30], and the photo is shown in Fig. 7. The simulation parameters are based on the real experimental working conditions: Hot water temperature ranges from $75^{\circ} \mathrm{C}$ to $95^{\circ} \mathrm{C}$ while the cooling water is $30^{\circ} \mathrm{C}$. The hot water and cooling water flowrate are $2.0 \mathrm{~m}^{3} \cdot \mathrm{h}^{-1}$ and $5 \mathrm{~m}^{3} \cdot \mathrm{h}^{-1}$, respectively. The conversion efficiency of the expander is considered as 0.6. The validated results of the ORC with TDP- $\mathrm{V}_{1}$ are shown in Fig. 8. Fig. 8a shows the instantaneous power output and pressure at $90^{\circ} \mathrm{C}$ heat 
source temperature and Fig. $8 \mathrm{~b}$ indicates the average power output at different heat source temperatures. It is demonstrated that the simulation results can well predict the thermal performance of ORC system with TDP- $\mathrm{V}_{1}$. For the instantaneous results, the average and largest deviation of the pressure and power output are $2.5 \%$ and $22.1 \%$, respectively. This is because the small power outputs cannot be tested by using electric bulb which makes electricity decline significantly in the end. Comparably, the main power generation process from $2 \mathrm{~min}$ to $6 \mathrm{~min}$ is accurately predicted. For average results, the deviation is no more than $5 \%$ at the temperature from $80^{\circ} \mathrm{C}$ to $95^{\circ} \mathrm{C}$. The largest deviation is around $24 \%$ at $75^{\circ} \mathrm{C}$ heat source temperature. This is due to the discontinues electric resistance i.e. bulb used in the experiment which results in some untested power output. For improved TDP series i.e. TDP- $\mathrm{V}_{2}$ to TDP- $\mathrm{V}_{\mathrm{n}}$, one heat exchanger is separated into two or more identical heat exchangers. Since each power generation cycle is considered as a repeatable process, identical heat exchangers with the same size are easy to achieve stable power output. In order to have a good comparison between ORC with TDP- $\mathrm{V}_{1}$ and improved TDP series, R245fa is selected as the refrigerant and total cycle time is set as 8 minutes for the simulation in this paper.

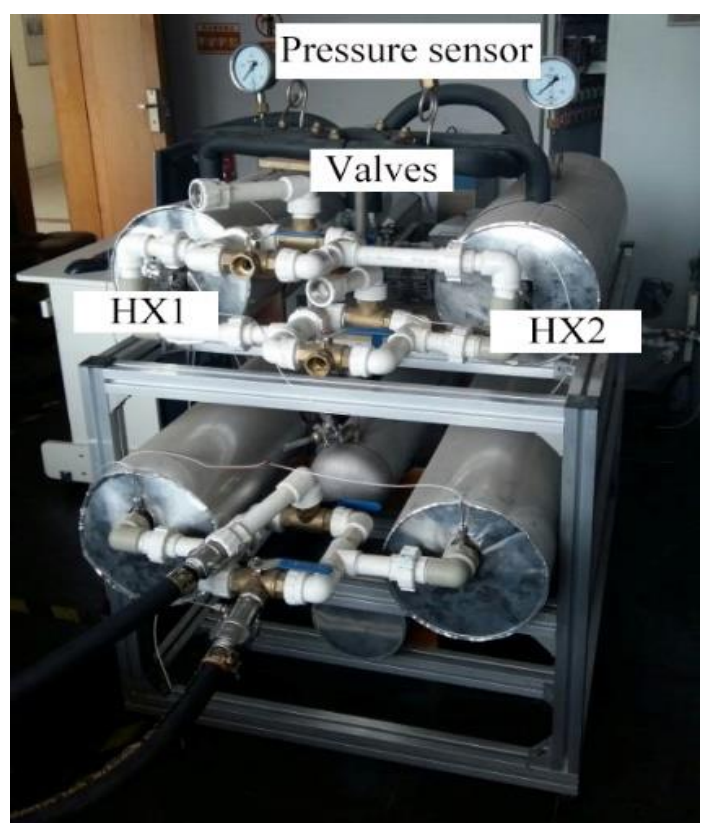

Fig. 7. Photo of ORC system with TDP-V $\mathrm{V}_{1}[30]$. 


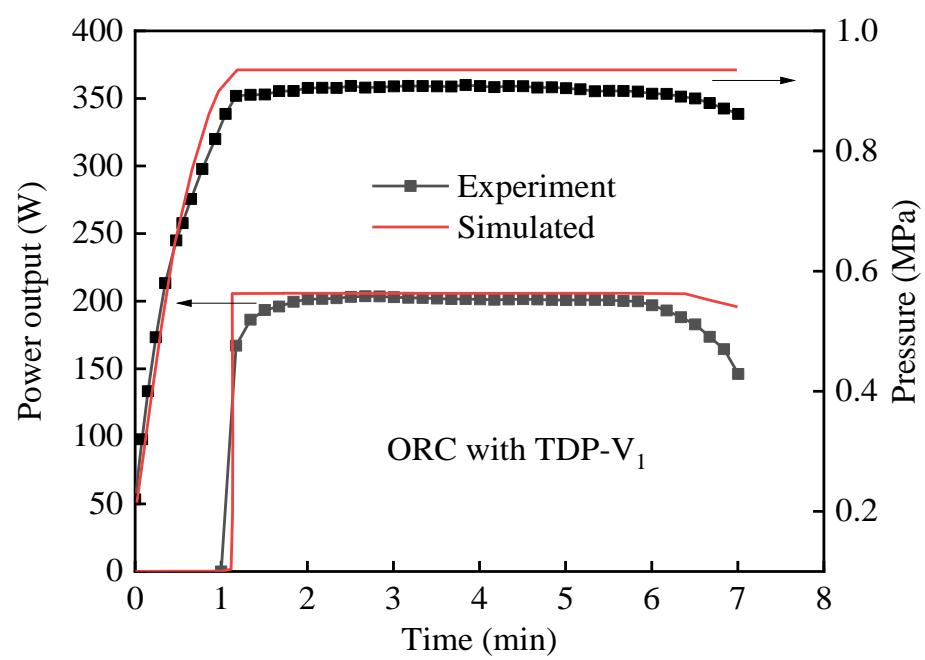

(a)

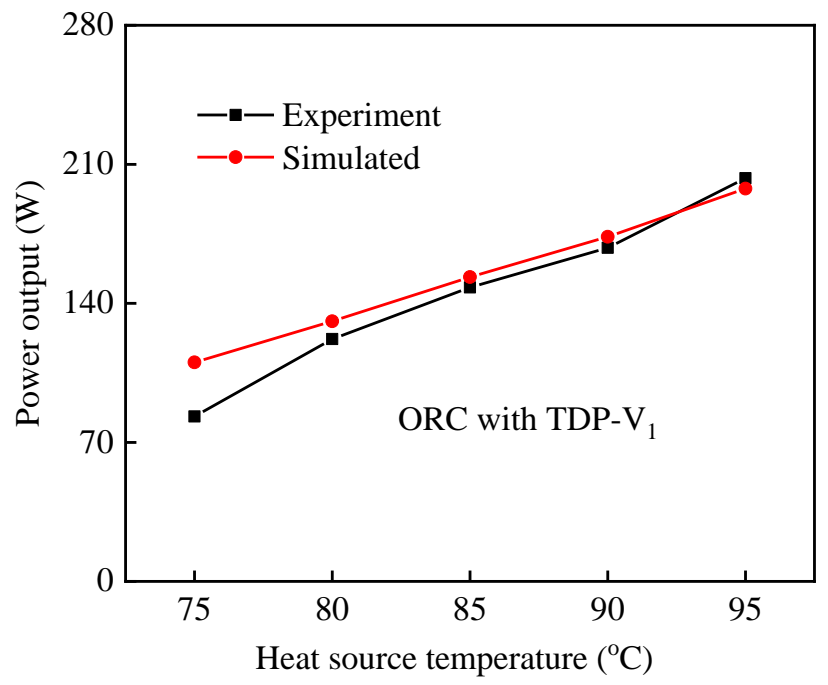

(b)

Fig. 8. The validation of the ORC with TDP-V 1 (a) instantaneous power output and pressure;

(b) average power output.

\section{Results and discussions}

\subsection{Thermal performance}

Fig. 9 reveals power output and heat input of ORC with TDP-V $\mathrm{V}_{1}$ and TDP-V $\mathrm{V}_{2}$ at different heat source temperatures from $75^{\circ} \mathrm{C}$ to $95^{\circ} \mathrm{C}$. It is indicated that both power output and heat input of ORC with TDP- $V_{2}$ are higher than that of ORC with TDP- $V_{1}$. The main reason is due to the increased power output which results from the larger heat transfer area and no pre-expansion time of TDP-V $\mathrm{V}_{1}$ 
Comparably, the increased heat input is mainly due to excessive heat for receiver and pipe. The power output by using TDP- $\mathrm{V}_{2}$ ranges from $158.8 \mathrm{~W}$ to $343.1 \mathrm{~W}$ which is improved by up to $73.5 \%$ when compared with that using TDP- $\mathrm{V}_{1}$. Similarly, heat input ranges from $7.87 \mathrm{~kW}$ to $9.23 \mathrm{~kW}$ which is increased by up to $44.5 \%$. Under this scenario, it is predicted that ORC with TDP- $\mathrm{V}_{2}$ is good to improve energy efficiency due to the increased power output.

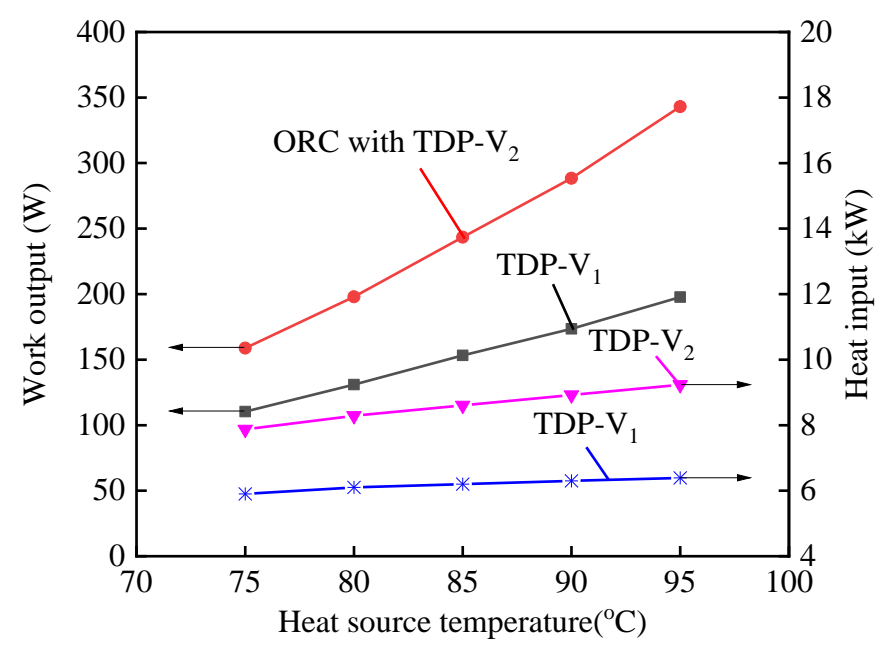

Fig. 9. Power output and heat input of the ORC with TDP- $V_{1}$ and TDP- $V_{2}$ vs. different heat source temperatures.

Fig. 10 demonstrates energy and exergy efficiencies of ORC with TDP- $\mathrm{V}_{1}, \mathrm{TDP}-\mathrm{V}_{2}$ and TDP- $\mathrm{V}_{3}$ which are also compared with their up-limit performance when the heat source temperature increases from $75^{\circ} \mathrm{C}$ to $95^{\circ} \mathrm{C}$. The up-limit performance of ORC using TDP- $\mathrm{V}_{\mathrm{n}}$ is defined when the number of heat exchangers in Fig. 6 tends to be infinite. As shown in Fig. 10a, energy efficiencies using TDP- $\mathrm{V}_{1}$, TDP- $\mathrm{V}_{2}$ and TDP- $\mathrm{V}_{3}$ increase with the increase of heat source temperature, which are in the range from 0.018 to 0.043 . The largest increment could reach $40.5 \%$, and the highest value accounts for $85 \%$ of the up-limit performance. It is demonstrated that the increased output using improved TDP series is larger than the increment of heat input. Fig. 10b indicates exergy efficiencies of ORC using with TDP series. Results indicate that exergy efficiencies also increase with the increase of heat source temperature, which range from 0.145 to 0.246 . The up-limit exergy efficiencies increase from 0.208 to 0.304 . One remarkable fact is that TDP- $\mathrm{V}_{2}$ and $\mathrm{TDP}-\mathrm{V}_{3}$ are prospective enough to improve thermal performance of the ORC which could achieve at least the $75 \%$ of the up-limit performance. 


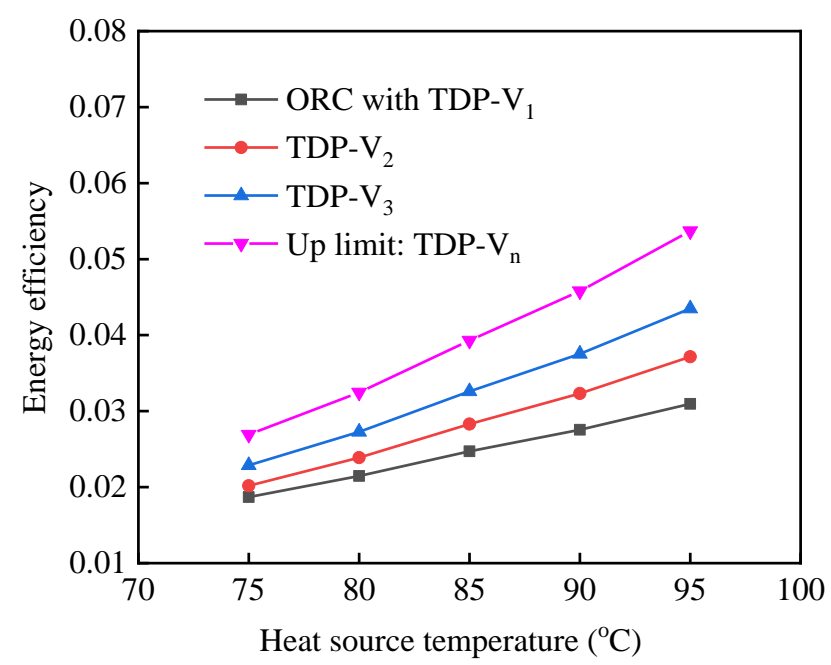

(a)

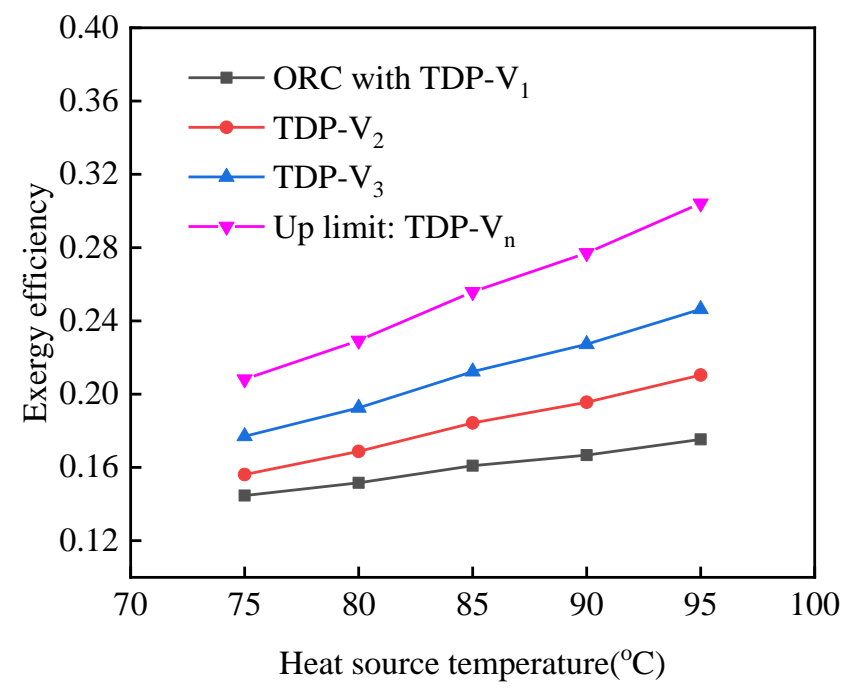

(b)

Fig. 10. Energy and exergy efficiencies of ORC with TDP series vs. different heat source temperatures (a) energy efficiency; (b) exergy efficiency.

\subsection{Flexibility analysis}

This section aims to investigate the influencing variables on thermal performance of the ORC with TDP series i.e. TDP- $V_{1}$ to TDP- $V_{n}$. Mass ratio is usually used to evaluate the performance in the possible applications when considering different thermal designs. As mentioned above, one heat exchanger could be separated into two or more heat exchangers, but one receiver and one condenser 
should be included for alternately heating and cooling. Mass ratio is defined as the specific value between mass of receiver and evaporator i.e. mass of receiver divided by mass of evaporator. Fig. 11 indicates energy and exergy efficiencies of ORC with TDP series in terms of different mass ratios. When mass ratio is 1 , it means that receiver have the same mass as the evaporator, i.e. it works as TDP- $\mathrm{V}_{1}$ and receiver plays a role as condenser. When mass ratio is 0.5 and $1 / 3$, it represents the TDP- $V_{2}$ and TDP- $V_{3}$, respectively. When mass ratio is 0 , it means the TDP- $V_{n}$ in which $N$ tends to be infinite. It is evident that energy efficiency decreases with the increase of mass ratio. As mass ratio increases from 0 to 1 , energy efficiencies of ORC with TDP series decrease from 0.049 to 0.028 at $95^{\circ} \mathrm{C}$ heat source temperature as shown in Fig. 11a. For different temperatures, energy efficiencies range from 0.016 to 0.049 . It is recommended that mass ratio is better within $0.3-0.6$. This is mainly because more pipes and connections are required in real application when number of divided reactors is increased. All these factors will increase the system complexity and difficulties to control. Receiver and condenser may be a bit larger than half capacity of evaporator. Fig. 11b indicates exergy efficiencies of ORC with improved TDP series. Different from energy efficiency, exergy efficiency is not so sensitive to heat source temperatures, especially for the temperature higher than $80^{\circ} \mathrm{C}$. Exergy efficiency decreases remarkably with the increase of mass ratio. It ranges from 0.279 to 0.161 when mass ratio increases from 0.1 to 1 .

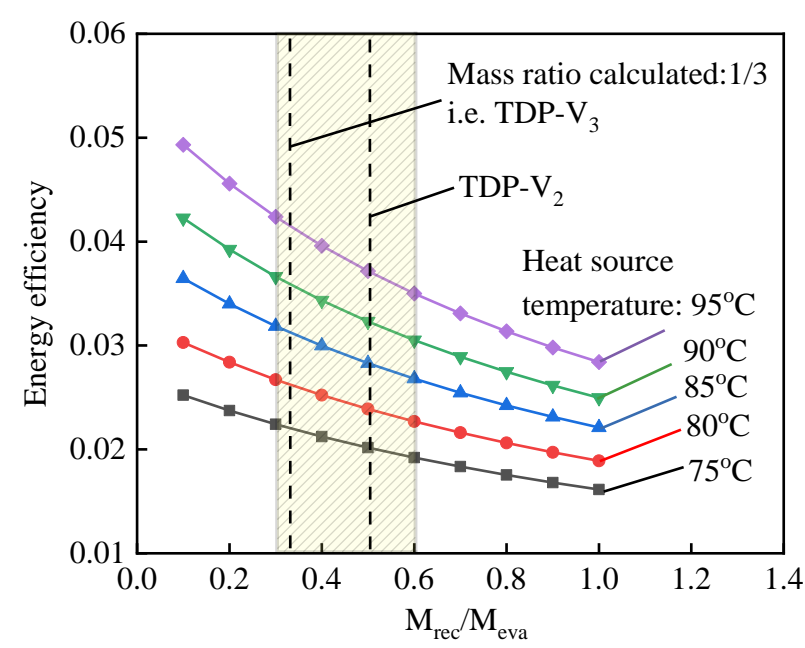

(a) 


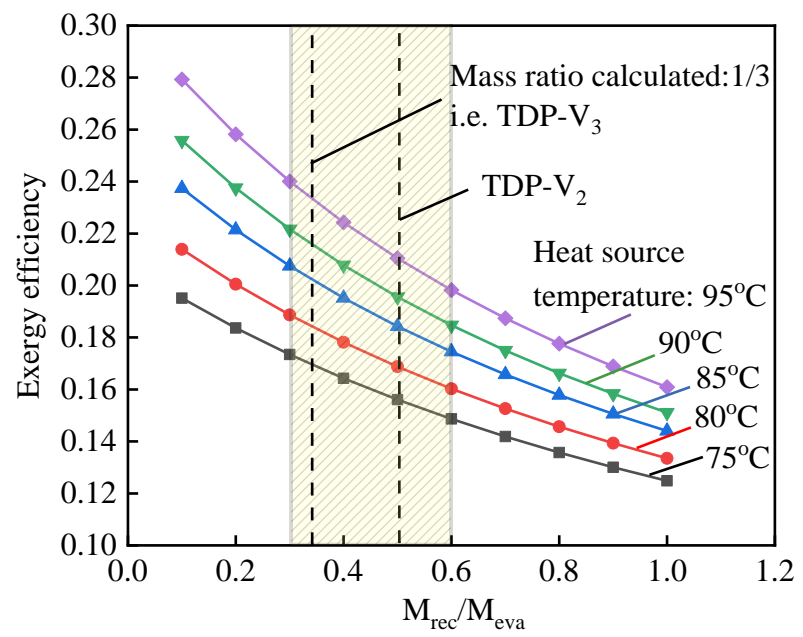

(b)

Fig. 11. Energy and exergy efficiencies of ORC with TDP series vs. different mass ratios (a) energy efficiency; (b) exergy efficiency.

Similar to real EDP, the efficiency of TDP is defined as power output divided by power input. By using volume changed inside receiver, pump efficiency is then transferred into equation 16 , i.e. volume of refrigerant output divided by the sum of volume output and volume residual. Volume residual inside receiver is filled with refrigerant vapour, which should have been used for power generation. Thus this part could cause the loss by using TDP series. Fig. 12 shows the relation between pump efficiency and volume ratio. It is extensively acknowledged that pump efficiency is usually higher than $70 \%$. The concerning ratio between volume residual and volume output should be less than 0.43 . Then representative energy and exergy efficiencies of ORC with improved TDP- $\mathrm{V}_{2}$ are shown in Fig. 13 when heat source temperature is $95^{\circ} \mathrm{C}$. The mass ratio is selected as 0.5 . It is indicated that energy and exergy efficiencies of ORC using TDP- $\mathrm{V}_{2}$ decrease with the increase of ratio between volume residual and volume output i.e. the decrease of pump efficiency. Also worth noting that exergy efficiency doesn't change greatly with the increase of volume ratio when compared with energy efficiency. When volume ratio is less than 0.43 , energy efficiencies decrease from 0.045 to 0.041 while exergy efficiencies range from 0.288 to 0.281 . After mass ratio is ensured i.e. the divided number $\mathrm{N}$, it is demonstrated that pump efficiency has a limited influence on energy and exergy efficiency of ORC with TDP series.

$$
\eta_{\text {pu }}=\frac{P_{\text {out }}}{P_{\text {in }}}=\frac{V_{\text {out }}}{V_{\text {out }}+V_{\text {res }}}
$$




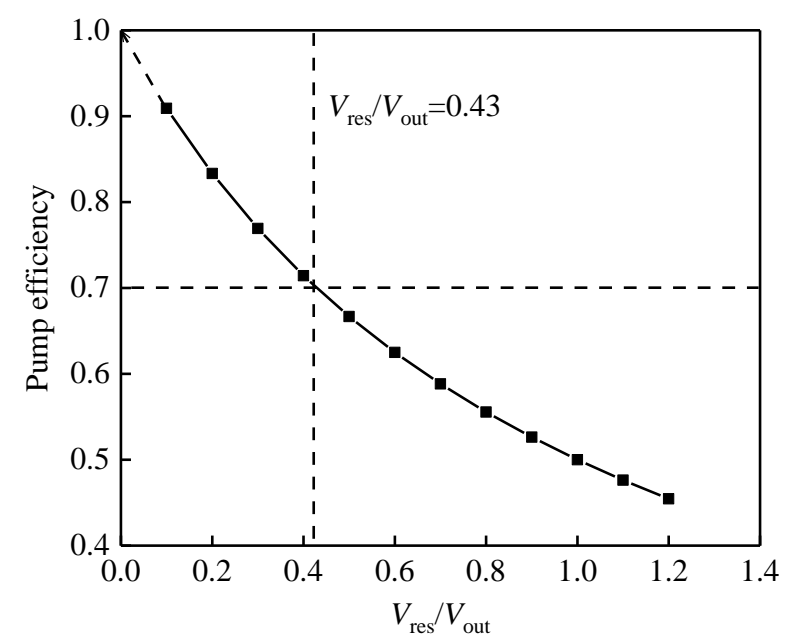

Fig. 12. Pump efficiency of TDP series vs. $V_{\text {res }} / V_{\text {out }}$.

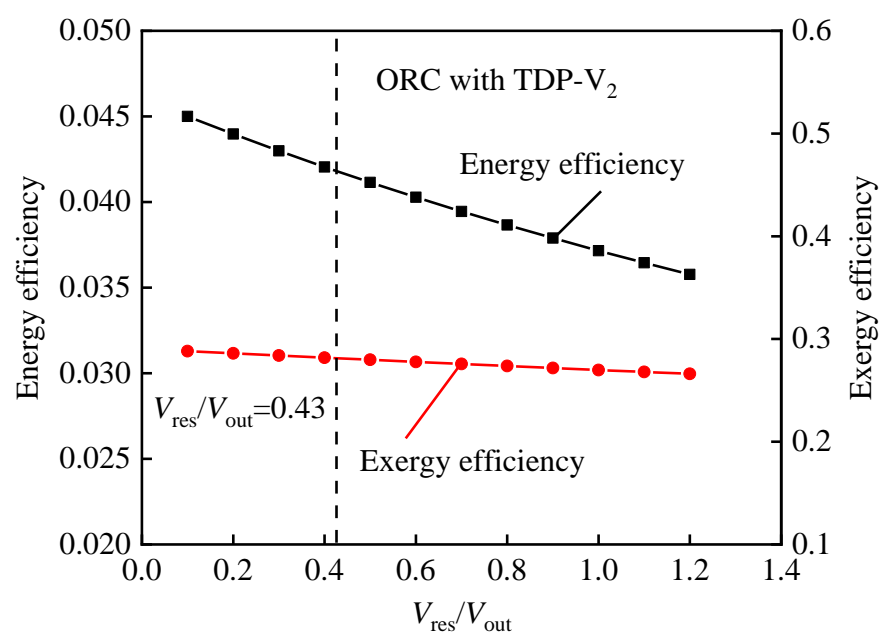

Fig. 13. Energy and exergy efficiencies of ORC with TDP-V $V_{2}$ vs. $V_{\text {res }} / V_{\text {out }}$.

\subsection{Economic feasibility}

It is evident that the thermal efficiency could be improved with the increase of the divided number of heat exchangers. However, the cost will also increase with the increase of heat exchangers and pipes. This section aims to investigate economic feasibility of the ORC with TDP series and find the desirable dividing number for the TDP technology. The module costing method is adopted to analyse the bare module cost of each component i.e. expander and heat exchangers according to equation 17. Chemical engineering plant cost index (CEPCI) is used to assess the capital cost of system according to equation 
18. Thus the specific investment cost (SIC) is defined as the capital cost dividing power output as shown in equation 19 .

$$
\begin{gathered}
\operatorname{Cost}_{2001}=C_{\mathrm{bm}, \mathrm{exp}}+\sum_{1}^{n} C_{b m, h x_{n}} \\
\operatorname{Cost}_{2017}=\operatorname{Cost}_{2001} \cdot C E P C I_{2017} / C E P C I_{2001} \\
\text { SIC }=\operatorname{Cost}_{2017} / \mathrm{W}
\end{gathered}
$$

where the coefficient for each component could refer to Table 3; $\mathrm{CEPCI}_{2001}=397.0$ and

\begin{tabular}{|c|c|c|c|c|c|c|}
\hline \multirow{2}{*}{ Components } & \multirow{2}{*}{ Cost models } & \multicolumn{5}{|c|}{ Coefficients } \\
\hline & & $\mathrm{K}_{1} / \mathrm{K}_{2} / \mathrm{K}_{3}$ & $\mathrm{C}_{1} / \mathrm{C}_{2} / \mathrm{C}_{3}$ & $\mathrm{~B}_{1} / \mathrm{B}_{2}$ & $F_{\mathrm{M}}$ & $F_{\text {bm }}$ \\
\hline Expander & $\begin{array}{l}C_{b m, \exp }=C_{p, \exp } F_{b m, \exp } \\
\lg C_{p, \exp }=K_{1, \exp }+K_{2, \exp } \\
\lg P_{\exp }+K_{3, \exp }\left(\lg P_{\exp }\right)^{2}\end{array}$ & $\begin{array}{l}\mathrm{K}_{1}=2.705 \\
\mathrm{~K}_{2}=1.440 \\
\mathrm{~K}_{3}=-0.17\end{array}$ & 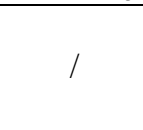 & / & / & 6.2 \\
\hline $\begin{array}{c}\text { Heat } \\
\text { exchanger }\end{array}$ & $\begin{array}{c}\mathrm{C}_{\mathrm{bm}, \mathrm{hx}}=\mathrm{C}_{\mathrm{p}, \mathrm{hx}} \mathrm{F}_{\mathrm{bm}, \mathrm{hx}} \\
\lg \mathrm{C}_{\mathrm{p}, \mathrm{hx}}=\mathrm{K}_{1, \mathrm{hx}}+\mathrm{K}_{2, \mathrm{hx}} \lg \mathrm{A}_{\mathrm{hx}}+\mathrm{K}_{3, \mathrm{hx}}\left(\lg \mathrm{A}_{\mathrm{hx}}\right)^{2} \\
\mathrm{~F}_{\mathrm{bm}, \mathrm{hx}}=\mathrm{B}_{1, \mathrm{hx}}+\mathrm{B}_{2, \mathrm{hx}} \mathrm{F}_{\mathrm{M}, \mathrm{hx}}\end{array}$ & $\begin{array}{c}\mathrm{K}_{1}=3.34 \\
\mathrm{~K}_{2}=0.2745 \\
\mathrm{~K}_{3}=-0.0472\end{array}$ & / & $\begin{array}{l}\mathrm{B}_{1}=0.96 \\
\mathrm{~B}_{2}=1.21\end{array}$ & 2.45 & l \\
\hline
\end{tabular}
$\mathrm{CEPCI}_{2017}=567.5$ are used to convert to present cost values in equation 19 [34].

Table 3. Investment models used to evaluate the ORC with TDPs [35].

Fig. 14 indicates the SICs of ORCs with TDP-V, TDP-V $V_{2}$ and TDP-V 3 in terms of different heat source temperatures. Results show that SICs decrease with the increase of the heat source temperature due to the increased power output. Besides, ORC with TDP-V 2 and TDP-V $\mathrm{V}_{3}$ have much lower SICs than that with TDP-V $\mathrm{V}_{1}$. This is mainly because the power output become continuous when the dividing number $\mathrm{N}$ is more than 1 and the heat transfer area of the evaporator is also increased. When heat source temperature increase from $75^{\circ} \mathrm{C}$ to $95^{\circ} \mathrm{C}$, SICs of ORC with TDP-V $\mathrm{V}_{1}$ decrease from 9156.4 $\$ \cdot \mathrm{kW}^{-1}$ to $6759.3 \$ \cdot \mathrm{kW}^{-1}$. When compared with those of ORC with TDP-V $\mathrm{V}_{2}$ and TDP-V $\mathrm{V}_{3}$, the results are up to $23.1 \%$ higher which demonstrate the advantage by using the improved TDP series. Also it can be found that the decrement of SICs by using TDP- $\mathrm{V}_{2}$ is much smaller. It is worth noting that SICs of ORC with TDP series are within the cost range of conventional ORC and the maximum SIC is lower than the reference value i.e. around $14000 \$ \cdot \mathrm{kW}^{-1}[35]$ which is quite promising among small-scale power generation technology for low temperature heat utilization.

In order to further investigate the economic characteristics, SICs of ORCs with TDP-V $\mathrm{V}_{1}$ to TDP- $V_{20}$ are evaluated at a heat source temperature of $95^{\circ} \mathrm{C}$ as shown in Fig. 15. One striking fact is that an inflection point happens with dividing number is around 3. The SIC sharply decreases from 
$6759.2 \$ \cdot \mathrm{kW}^{-1}$ i.e. ORC with $\mathrm{TDP}-\mathrm{V}_{1}$ to the lowest value $5772.6 \$ \cdot \mathrm{kW}^{-1}$ i.e. ORC with TDP-V $\mathrm{V}_{3}$, then increases with the increase of the dividing number $\mathrm{N}$. This is mainly because the investment cost is greatly increased by using improved TDP series i.e. $V_{2}$ to $V_{n}$ in terms of the heat exchangers, pipeline, and valves. Comparably, thermal efficiencies of the ORC with improved TDP series are not increased accordingly when dividing number $\mathrm{N}$ becomes larger. From the perspective of cost and system complexity, it is recommended that the dividing number should be no more than 4 . Also, the scale of ORC is suggested to be lower than $10 \mathrm{~kW}$. Otherwise TDP will not be advantageous when compared with conventional ORC since the pump work accounts for less percentage of the total power output.

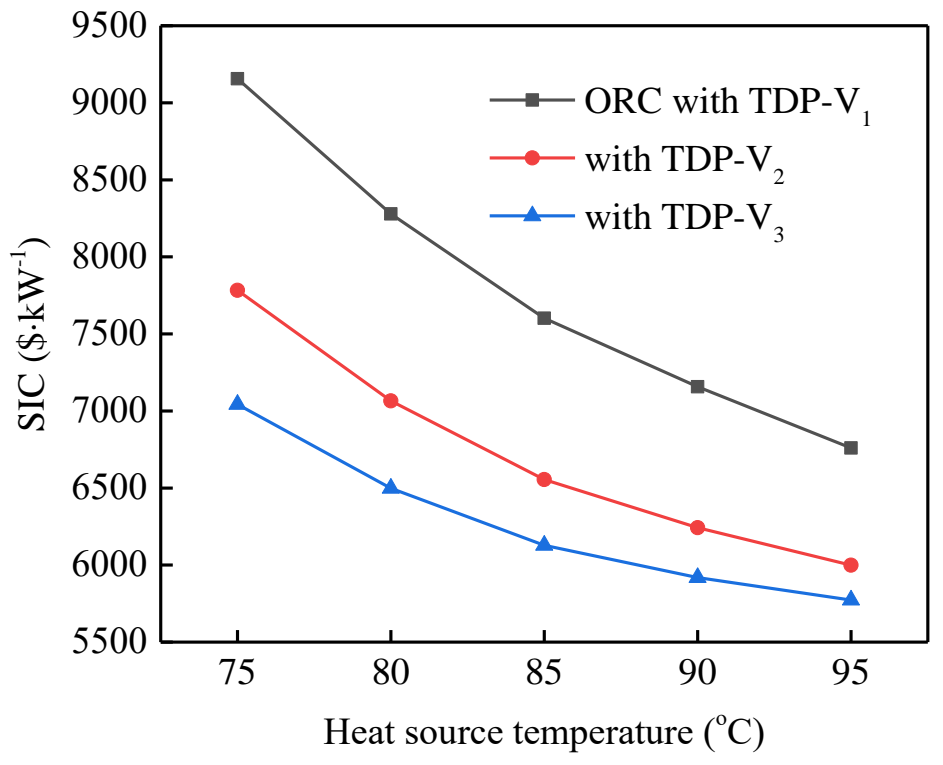

Fig. 14. SICs of ORCs with TDP-V $1, T D P-V_{2}$ and TDP-V $V_{3}$ vs. different heat source temperatures. 


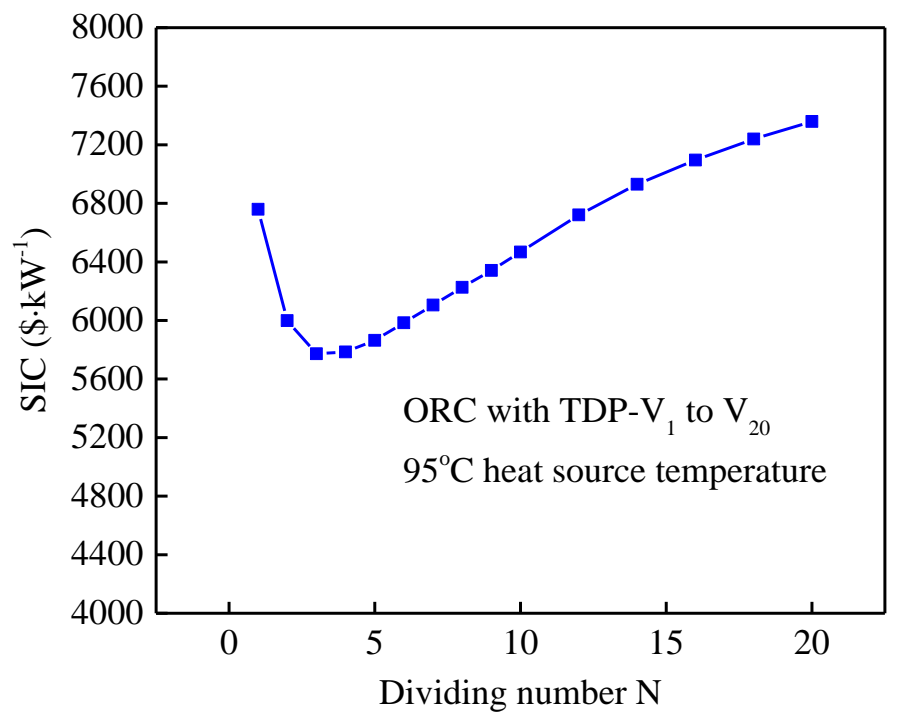

Fig. 15. SICs of ORCs with TDP-V $\mathrm{V}_{1}$ to TDP-V $\mathrm{V}_{20}$.

\subsection{Further exploration and comparison}

This section is to comprehensively compare conventional ORC, ORC with TDP and ORC with improved TDP series in terms of system compactness, power output, thermal efficiency and capital cost which are shown in Table 4. ORC with improved TDP series are similar with conventional ORC as the continuous system while ORC with TDP is the intermittent system. For system compactness, ORC with TDP- $V_{1}$ has the smaller size than that of the conventional ORC due to the elimination of EDP. The sizes of ORC with improved series increase with the increase of dividing number $\mathrm{N}$ due to its system complexity. Besides, conventional ORC shows the more stable power output that those of ORC with improved TDP series. This is mainly because of the switch interval between condenser and receiver though it could realize the continuous output. ORC with TDP-V 1 shows the poorest power output since it doesn't generate the electricity during the pre-expansion process. Based on aforementioned analysis, energy and exergy efficiencies of ORC with improved TDP series are much higher than that using TDP-V $V_{1}$. The increment between performance of ORC with TDP series and conventional type becomes larger when the number $\mathrm{N}$ is increased. Total capital cost increases with the increases of the number $\mathrm{N}$. Since cost of EDP is usually 3-4 times higher than that of heat exchanger, the total cost of ORC with TDP-V $\mathrm{V}_{1}$ could be reduced by around $10 \%$ when compared with total cost of the conventional ORC system. The cost of TDP-V $\mathrm{V}_{4}$ could be similar with that of conventional ORC. 
Table 4. Comparison among conventional ORC and ORC with TDP series.

\begin{tabular}{cccccc}
\hline Type & System type & $\begin{array}{c}\text { System } \\
\text { compactness }\end{array}$ & $\begin{array}{c}\text { Output } \\
\text { stability }\end{array}$ & Energy efficiency & SIC \\
\hline $\begin{array}{c}\text { Conventional } \\
\text { ORC }\end{array}$ & Continuous & Moderate & High & Low & High \\
ORC with & Intermittent & High & Low & Moderate & At least $10 \%$ \\
TDP-V $\mathrm{V}_{1}$ & Continuous & Moderate & Moderate & High & At least $8 \%$ \\
ORC with & less & less \\
TDP-V $\mathrm{V}_{2}$ & Continuous & $\begin{array}{c}\text { Decrease with } \\
\text { number } \mathrm{N}\end{array}$ & $\begin{array}{c}\text { Increase with } \\
\text { number } \mathrm{N}\end{array}$ & $\begin{array}{c}\text { Increase with } \\
\text { number } \mathrm{N}\end{array}$ & $\begin{array}{c}\text { Similar with } \\
\text { TDP- }\end{array}$ \\
\hline
\end{tabular}

In order to further clarify the novelty of this paper, ORCs with improved TDP series are comprehensively compared with other selected studies of power cycles by using gravity and thermal driven pumps, which are demonstrated in Table 5. The main technologies to eliminate the pump of power cycle could be classified into two types. One is to use several reactors with different heating and cooling modes at intervals. The other is heat pipe i.e. thermosiphon method for power generation. Compared with the first method, the second method is quite difficult to be adopted in real application. Although energy efficiency of thermosiphon is reasonable, power output is relatively low. ORC by using gravity driven pump could be a good candidate if the required height and power demands could be satisfied. It is demonstrated that cycles with TDP series have been improved remarkably since it is first proposed. The power output is improved from several watts to hundreds of watts, and energy efficiency for electricity output could reach up to $2.4 \%$ with a relatively high thermal stability. ORC with improved TDP series in the present work could further increase the stability of power output while the high energy efficiency is remained. This novel concept could be an alternative method of conventional ORC for recovering low temperature heat source especially for domestic solar thermal utilization. Control strategy and optimization are predicted to be key research targets for this technology when considering the experiment in the near future.

Table 5. Comparison among various selected power cycles with gravity and thermal driven pumps.

\begin{tabular}{llll}
\hline Research method $\quad$ Working fluid & Description and novelty
\end{tabular}




\begin{tabular}{|c|c|c|c|}
\hline $\begin{array}{l}\text { Performance } \\
\text { analysis }\end{array}$ & $\begin{array}{l}\text { R123, R245ca, } \\
\text { R113, PF5050, } \\
\text { PF5060 }\end{array}$ & $\begin{array}{l}\text { Gravity is used to pressurize the working fluid; The } \\
\text { minimum required height is about } 20.9 \mathrm{~m} \text {; The highest } \\
\text { energy efficiency is } 10.93 \% \text {. }\end{array}$ & [36] \\
\hline $\begin{array}{l}\text { Analysis\& } \\
\text { Experiment }\end{array}$ & R245fa & $\begin{array}{l}\text { Switching of valves is employed to control the cycle; The } \\
\text { maximum power out and energy efficiency are } 7.2 \mathrm{~W} \text { and } \\
\qquad 0.24 \% \text {. }\end{array}$ & [28] \\
\hline Experiment & $\mathrm{R} 245 \mathrm{fa}$ & $\begin{array}{l}\text { ORC is improved with TDP; The maximum power out is } \\
20 \mathrm{~W} \text { and energy efficiency is } 0.5 \% \text {. }\end{array}$ & [37] \\
\hline Experiment & $\mathrm{R} 245 \mathrm{fa}$ & $\begin{array}{l}\text { ORC is improved by using TDP; Average power out is } \\
156 \mathrm{~W} \text {; Energy efficiency for work output is } 2.3 \% \text {. } \\
\text { ORC is improved using TDP; Average power out is } 204\end{array}$ & [29] \\
\hline Experiment & $\mathrm{R} 245 \mathrm{fa}$ & $\begin{array}{l}\text { W; Energy efficiency for electricity output is } 2.4 \% \text { with } \\
\text { higher thermal stability. }\end{array}$ & [30] \\
\hline $\begin{array}{l}\text { Performance } \\
\text { analysis }\end{array}$ & Carbon dioxide & $\begin{array}{l}\text { Rankine power cycle is proposed with TDP. Heat source } \\
\text { temperature is } 60^{\circ} \mathrm{C} \text {. }\end{array}$ & [38] \\
\hline $\begin{array}{l}\text { Performance } \\
\text { analysis }\end{array}$ & Carbon dioxide & Thermosiphon generation is driven by geothermal power. & [39] \\
\hline Experiment & Water & $\begin{array}{l}\text { Thermosiphon Rankine engine is proposed for power } \\
\text { output; The maximum power out is } 5.5 \mathrm{~W} \text { and energy } \\
\text { efficiency is } 0.125 \% \text {. }\end{array}$ & [40] \\
\hline $\begin{array}{l}\text { Performance } \\
\text { analysis }\end{array}$ & Water & $\begin{array}{l}\text { Enhanced thermosiphon Rankine cycle using } \\
\text { impulse turbine; The highest energy efficiency is } 2.854 \% \text {. }\end{array}$ & [41] \\
\hline $\begin{array}{l}\text { Performance } \\
\text { analysis }\end{array}$ & Water & $\begin{array}{l}\text { Heat pipe turbine cycle is analyzed and designed in terms } \\
\text { of geometric and thermodynamic parameters. }\end{array}$ & [42] \\
\hline Analysis & R245fa & $\begin{array}{l}\text { The maximum energy and exergy efficiency are } 5.3 \% \text { and } \\
\qquad 30.4 \% \text {, respectively. }\end{array}$ & $\begin{array}{l}\text { Present } \\
\text { study }\end{array}$ \\
\hline
\end{tabular}

\section{Conclusions}

In this paper, improved TDP series are presented to evaluate its limitation and influence on the technical and economic performance of the ORC in terms of power output, heat input, efficiency, thermal up-limit performance and SIC. Besides, performance of ORCs with TDP series are compared with that of conventional ORC. Conclusions are yielded as follows:

(1) Power output and heat input increase with the increase of heat source temperature. Power output by using TDP- $\mathrm{V}_{2}$ ranges from $158.8 \mathrm{~W}$ to $343.1 \mathrm{~W}$ which is improved by up to $73.5 \%$ when compared with that using $\mathrm{TDP}-\mathrm{V}_{1}$. When the temperature increase from $75^{\circ} \mathrm{C}$ to $95^{\circ} \mathrm{C}$, energy efficiencies using TDP- $\mathrm{V}_{1}$ to $\mathrm{TDP}-\mathrm{V}_{3}$ increase from 0.018 to 0.043 . The largest increment could reach $40.5 \%$, and the highest value accounts for $85 \%$ of up-limit performance. 
Similarly, exergy efficiencies range from 0.145 to 0.246 . The up-limit exergy efficiencies increase from 0.208 to 0.304 .

(2) Energy efficiency decreases with the increase of mass ratio between mass of receiver and evaporator. As mass ratio increases from 0.1 to 1 , energy efficiencies of ORC with TDP series decrease from 0.049 to 0.028 at $95^{\circ} \mathrm{C}$ heat source temperature. For different temperatures, energy efficiencies range from 0.016 to 0.049 . It is recommended that mass ratio is better within 0.3-0.6 when considering real application. Exergy efficiencies of ORC with TDP series range from 0.279 to 0.161 when mass ratio increases from 0.1 to 1 .

(3) When heat source temperature increases from $75^{\circ} \mathrm{C}$ to $95^{\circ} \mathrm{C}$, SICs of ORC with TDP- $\mathrm{V}_{1}$ decrease from $9156.4 \$ \cdot \mathrm{kW}^{-1}$ to $6759.3 \$ \cdot \mathrm{kW}^{-1}$. When compared with those of ORC with TDP- $V_{2}$ and TDP- $V_{3}$, the results are up to $23.1 \%$ higher. The SIC is sharply decreased from $6759.2 \$ \cdot \mathrm{kW}^{-1}$ i.e. $\mathrm{ORC}$ with $\mathrm{TDP}-\mathrm{V}_{1}$ to the lowest value $5772.6 \$ \mathrm{~kW}^{-1}$ i.e. ORC with TDP- $\mathrm{V}_{3}$, then increased with the increase of the dividing number N. It is recommended that TDP series should be applied into ORC under the conditions of low capacity less than $10 \mathrm{~kW}$, small dividing number i.e. smaller than 4 and low heat source temperature.

With the wide utilization of the renewable energy, the proposed ORC with TDP series may be an alternative method for recovering low temperature heat source. One suitable application is the domestic household electricity supply driven by the solar thermal collector especially in the remote place e.g. tropic islands since the high thermal efficiency of ORC with TDP series could bring more benefits to the end user. Besides, this technology could flexibly be integrated with other technologies e.g. solar cooling and heating, which could provide small-scale energy outputs to meet the various demands of a family.

Acknowledgments: This research was supported by European Union's Horizon 2020 Research and Innovation Programme under grant number (895767) and National Natural Science Foundation of China under contract number (51606118).

\section{References}

[1] Lu H, Price L, Zhang Q. Capturing the invisible resource: Analysis of waste heat potential in Chinese industry. Applied Energy. 2016;161:497-511. 
[2] Zhang M-G, Zhao L-J, Xiong Z. Performance evaluation of organic Rankine cycle systems utilizing low grade energy at different temperature. Energy. 2017;127:397-407.

[3] Vivian J, Manente G, Lazzaretto A. A general framework to select working fluid and configuration of ORCs for low-to-medium temperature heat sources. Applied Energy. 2015;156:727-46.

[4] Zhang Z, Alelyani SM, Zhang N, Zeng C, Yuan Y, Phelan PE. Thermodynamic analysis of a novel sodium hydroxide-water solution absorption refrigeration, heating and power system for low-temperature heat sources. Applied Energy. 2018;222:1-12.

[5] Cioccolanti L, Tascioni R, Arteconi A. Mathematical modelling of operation modes and performance evaluation of an innovative small-scale concentrated solar organic Rankine cycle plant. Applied Energy. 2018;221:464-76.

[6] Shi L, Shu G, Tian H, Deng S. A review of modified Organic Rankine cycles (ORCs) for internal combustion engine waste heat recovery (ICE-WHR). Renewable and Sustainable Energy Reviews. 2018;92:95-110.

[7] Braimakis K, Karellas S. Energetic optimization of regenerative Organic Rankine Cycle (ORC) configurations. Energy Conversion and Management. 2018;159:353-70.

[8] Sun H, Qin J, Yan P, Huang H, Hung T-C. Performance evaluation of a partially admitted axial turbine using R245fa, R123 and their mixtures as working fluid for small-scale organic Rankine cycle. Energy Conversion and Management. 2018;171:925-35.

[9] Wang XD, Zhao L, Wang JL. Experimental investigation on the low-temperature solar Rankine cycle system using R245fa. Energy Conversion and Management. 2011;52:946-52.

[10] Bao J, Zhao L. A review of working fluid and expander selections for organic Rankine cycle. Renewable and Sustainable Energy Reviews. 2013;24:325-42.

[11] Liu B-T, Chien K-H, Wang C-C. Effect of working fluids on organic Rankine cycle for waste heat recovery. Energy. 2004;29:1207-17.

[12] Chen H, Goswami DY, Stefanakos EK. A review of thermodynamic cycles and working fluids for the conversion of low-grade heat. Renewable and Sustainable Energy Reviews. 2010;14:3059-67.

[13] Bamorovat Abadi G, Kim KC. Investigation of organic Rankine cycles with zeotropic mixtures as a working fluid: Advantages and issues. Renewable and Sustainable Energy Reviews. 2017;73:1000-13.

[14] Xu W, Deng S, Zhao L, Su W, Zhang Y, Li S, et al. How to quantitatively describe the role of the 
pure working fluids in subcritical organic Rankine cycle: A limitation on efficiency. Energy Conversion and Management. 2018;172:316-27.

[15] Tchanche BF, Lambrinos G, Frangoudakis A, Papadakis G. Low-grade heat conversion into power using organic Rankine cycles - A review of various applications. Renewable and Sustainable Energy Reviews. 2011;15:3963-79.

[16] Al-Sulaiman FA, Dincer I, Hamdullahpur F. Energy and exergy analyses of a biomass trigeneration system using an organic Rankine cycle. Energy. 2012;45:975-85.

[17] Xu W, Deng S, Zhao L, Zhao D, Chen R. Identification of key affecting parameters of zeotropic working fluid on subcritical organic Rankine cycle according limiting thermodynamic cycle. Energy Conversion and Management. 2019;197:111884.

[18] Shahverdi K, Loni R, Ghobadian B, Monem MJ, Gohari S, Marofi S, et al. Energy harvesting using solar ORC system and Archimedes Screw Turbine (AST) combination with different refrigerant working fluids. Energy Conversion and Management. 2019;187:205-20.

[19] Li T, Meng N, Liu J, Zhu J, Kong X. Thermodynamic and economic evaluation of the organic Rankine cycle (ORC) and two-stage series organic Rankine cycle (TSORC) for flue gas heat recovery. Energy Conversion and Management. 2019;183:816-29.

[20] Zhao Y, Liu G, Li L, Yang Q, Tang B, Liu Y. Expansion devices for organic Rankine cycle (ORC) using in low temperature heat recovery: A review. Energy Conversion and Management. 2019;199:111944.

[21] Hou X, Zhang H, Yu F, Liu H, Yang F, Xu Y, et al. Free piston expander-linear generator used for organic Rankine cycle waste heat recovery system. Applied Energy. 2017;208:1297-307.

[22] Zheng X, Luo X, Luo J, Chen J, Liang Y, Yang Z, et al. Experimental investigation of operation behavior of plate heat exchangers and their influences on organic Rankine cycle performance. Energy Conversion and Management. 2020;207:112528.

[23] Zeleny Z, Vodicka V, Novotny V, Mascuch J. Gear pump for low power output ORC - an efficiency analysis. Energy Procedia. 2017;129:1002-9.

[24] Yang Y, Zhang H, Tian G, Xu Y, Wang C, Gao J. Performance Analysis of a Multistage Centrifugal Pump Used in an Organic Rankine Cycle (ORC) System under Various Condensation Conditions. Journal of Thermal Science. 2019;28:621-34. 
[25] Jang Y, Lee J. Comprehensive assessment of the impact of operating parameters on sub 1-kW compact ORC performance. Energy Conversion and Management. 2019;182:369-82.

[26] Tahir MBINM, Yamada N. Characteristics of Small ORC System for Low Temperature Waste Heat Recovery. Journal of Environment and Engineering. 2009;4:375-85.

[27] Kim DK, Lee JS, Kim J, Kim MS, Kim MS. Parametric study and performance evaluation of an organic Rankine cycle (ORC) system using low-grade heat at temperatures below $80^{\circ} \mathrm{C}$. Applied Energy. 2017;189:55-65.

[28] Yamada N, Minami T, Anuar Mohamad MN. Fundamental experiment of pumpless Rankine-type cycle for low-temperature heat recovery. Energy. 2011;36:1010-7.

[29] Gao P, Wang LW, Wang RZ, Jiang L, Zhou ZS. Experimental investigation on a small pumpless ORC (organic rankine cycle) system driven by the low temperature heat source. Energy. 2015;91:324-33. [30] Jiang L, Lu HT, Wang LW, Gao P, Zhu FQ, Wang RZ, et al. Investigation on a small-scale pumpless Organic Rankine Cycle (ORC) system driven by the low temperature heat source. Applied Energy. 2017;195:478-86.

[31] Wang R, Jiang L, Ma Z, Gonzalez-Diaz A, Wang Y, Roskilly AP. Comparative Analysis of Small-Scale Organic Rankine Cycle Systems for Solar Energy Utilisation. Energies. 2019;12:829.

[32] Dong M, Xia ZZ, Du S, Wang R. Characteristic of respiratory pump employed in small-capacity ammonia-water absorption refrigeration system. Building Energy\&Environment. 2014;33:1-5.

[33] Wang ZX, Du S, Wang LW, Chen X. Parameter analysis of an ammonia-water power cycle with a gravity assisted thermal driven "pump" for low-grade heat recovery. Renewable Energy. 2020;146:651-61.

[34] Chemical Engineering Index (2018). Available online at: www.chemengonline. com/cepci-updates-january-2018-prelim-and-december-2017-final (accessed January 6, 2019).

[35] Shu G, Yu G, Tian H, Wei H, Liang X. A Multi-Approach Evaluation System (MA-ES) of Organic Rankine Cycles (ORC) used in waste heat utilization. Applied Energy. 2014;132:325-38.

[36] Li J, Pei G, Li Y, Ji J. Analysis of a novel gravity driven organic Rankine cycle for small-scale cogeneration applications. Applied Energy. 2013;108:34-44.

[37] Yamada N, Watanabe M, Hoshi A. Experiment on pumpless Rankine-type cycle with scroll expander. Energy. 2013;49:137-45. 
[38] Lakew AA, Bolland O, Ladam Y. Theoretical thermodynamic analysis of Rankine power cycle with thermal driven pump. Applied Energy. 2011;88:3005-11.

[39] Atrens AD, Gurgenci H, Rudolph V. CO2 Thermosiphon for Competitive Geothermal Power Generation. Energy \& Fuels. 2009;23:553-7.

[40] Nguyen T, Johnson P, Akbarzadeh A, Gibson K, Mochizuki M. Design, manufacture and testing of a closed cycle thermosyphon rankine engine. Heat Recovery Systems and CHP. 1995;15:333-46.

[41] Ziapour BM. Performance analysis of an enhanced thermosyphon Rankine cycle using impulse turbine. Energy. 2009;34:1636-41.

[42] Akbarzadeh A, Johnson P, Nguyen T, Mochizuki M, Mashiko M, Sauciuc I, et al. Formulation and analysis of the heat pipe turbine for production of power from renewable sources. Applied Thermal Engineering. 2001;21:1551-63. 